\title{
Effectiveness of a Retrospective Drug Utilization Review on Potentially Unsafe Opioid and Central Nervous System Combination Therapy
}

\author{
Nabeel Qureshi, PharmD, MPH; Laurie A. Wesolowicz, PharmD; \\ Chi-Mei Liu, MA, MBA; and Alexandra Tungol Lin, PharmD
}

\begin{abstract}
BACKGROUND: Drug overdose deaths are the leading cause of unintentional death in the United States, and opioid-related mortality is the primary contributor (75.2\%). Among opioid-related mortalities, opioids are most commonly taken with benzodiazepines $(30.1 \%)$ and antidepressants (13.4\%). The utility of a retrospective drug utilization review (DUR) program initiated by a commercial health plan for members taking potentially unsafe opioid and central nervous system (CNS) combination therapy is currently unknown.
\end{abstract}

OBJECTIVE: To determine the effectiveness of a retrospective DUR program on potentially unsafe opioid and CNS combination therapy.

METHODS: This research is a pre-post study utilizing pharmacy claims data from 2.6 million commercially insured members enrolled in a health plan in the Midwest. Members were required to be at least aged 18 years as of August 30, 2013, and continuously enrolled from May 2, 2013, through February 15, 2014. Members with 1 or more paid claims for an opioid at least 200 morphine equivalent dose (MED) daily and a concurrent supply of another opioid, benzodiazepine, or antidepressant from May 2, 2013, through August 30, 2013 (120-day preintervention period) were targeted for the retrospective DUR program. These exclusion criteria were applied: members belonging to commercial groups requiring permission on claims data analyses, missing or invalid prescriber information, or presence of pharmacy claims indicating human immunodeficiency virus or acquired immunodeficiency syndrome during the 2 years prior to the pre-intervention period. Prescribers of high-dose opioids received a mailing (intervention) containing a member-specific letter, medication profile, and satisfaction survey to determine the prescriber-perceived clinical value of the program. To assess the effectiveness of the retrospective DUR program, criteria was reapplied to identify members still meeting criteria 120 days postintervention (February 15, 2014). Paired samples t-test was used to compare pre-post results.

RESULTS: Of 2,236,243 eligible members aged 18 years and older, 980 met DUR criteria. Prescribers for these members subsequently received a mailing regarding potentially unsafe opioid and CNS combination therapy. A total of 671 prescribers were sent a mailing regarding these 980 members. Among the 980 members meeting DUR criteria, distribution of prescriber specialty was family medicine $(25.9 \%)$, physical medicine and rehabilitation $(14.4 \%)$, internal medicine $(13.0 \%)$, pain $(9.2 \%)$, anesthesiology $(7.0 \%)$, other (8.8\%), and unknown (21.7\%). High-dose opioids most commonly identified by the DUR were oxycodone extended release $(27.6 \%)$, morphine sulfate extended release (17.7\%), and fentanyl patch (13.1\%). After reapplying DUR criteria to identify members still meeting criteria 120 days after the DUR, 528 members remained, representing a $28.1 \%$ reduction in high-risk opioid use. Survey response rate was $23.6 \%$ (231 of 980 surveys returned). The majority $(62.3 \%)$ of respondents reported that this retrospective DUR program was useful in their daily practice.
CONCLUSIONS: A $28.1 \%$ reduction in potentially unsafe opioid and CNS combination therapy was observed after implementing a retrospective DUR program targeting high-risk opioid use. Among members remaining high risk after the DUR, the change in total unique opioids and total daily MED was nonsignificant. Members remaining at high risk after the DUR can be targeted for further interventions such as care management and member education regarding fraud, waste, and abuse. A majority of prescribers (90.5\%) self-report using their states' prescription monitoring programs when prescribing controlled substances.

\section{J Manag Care Spec Pharm. 2015;21(10):938-44}

Copyright $\odot 2015$, Academy of Managed Care Pharmacy. All rights reserved.

\section{What is already known about this subject}

From 1990 to 2010, drug overdose deaths increased from 3.4 per 100,000 to 12.4 per 100,000 , an increase of approximately $300 \%$. Opioids are primarily responsible for the increase in drug overdose mortality, accounting for $75.2 \%$ of cases.

Among opioid-related mortalities, opioids are most commonly taken with benzodiazepines (30.1\%) and antidepressants (13.4\%).

\section{What this study adds}

A commercial health plan implemented a retrospective drug utilization review (DUR) program targeting high-risk opioid use and observed a $28.1 \%$ reduction in such utilization

Among a commercially insured population, high dose opioids most commonly identified by a retrospective DUR program were oxycodone extended release (27.6\%), morphine sulfate extended release (17.7\%), and fentanyl patch (13.1\%).

The majority (90.5\%) of prescribers self-reported using their states' prescription monitoring programs when treating patients with controlled substances.

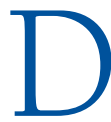
rug overdose deaths are the leading cause of unintentional death in the United States and increased for the eleventh straight year in 2010.,2 From 1990 to 2010, drug overdose deaths increased from 3.4 per 100,000 to 12.4 per 100,000, an increase of approximately $300 \% .3,4$ Opioids are the most common drug class involved in drug overdose deaths, with patients taking opioids in three fourths of cases. ${ }^{1}$ Doses greater than 100 morphine equivalent dose (MED) daily are associated with 11 times greater risk for opioid-related overdose death. ${ }^{5}$ Additionally, concomitant use of benzodiazepines 
120-day preintervention time period 120-day postintervention time period

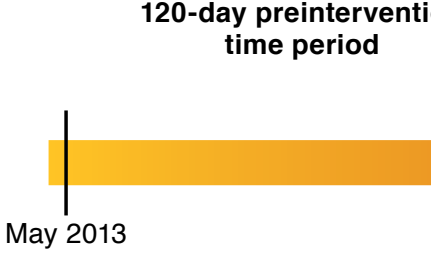

May 2013

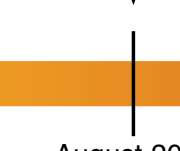

August 2013

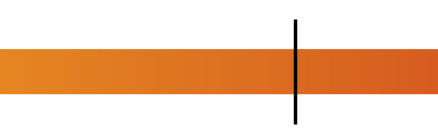

October 2013

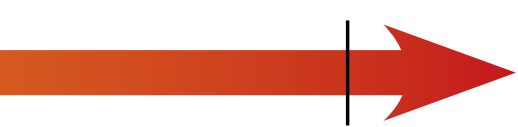

February 2014 and antidepressants are most often involved in opioid-related mortalities, $30.1 \%$ and $13.4 \%$, respectively. ${ }^{6}$

The Centers for Disease Control and Prevention (CDC) classify drug overdose as an epidemic. ${ }^{7}$ To combat the drug overdose epidemic, the CDC recommends the following: prescription drug monitoring programs (PDMPs), patient review and restriction programs, health care provider accountability, laws to prevent prescription drug abuse and diversion, and better access to substance abuse treatment. Retrospective drug utilization review (DUR) programs are a mechanism to monitor prescription claims information and have been successful in many different patient populations. ${ }^{8}$ However, the value of a retrospective DUR program for potentially unsafe opioid and central nervous system (CNS) combination therapy is unknown. A retrospective DUR program can identify members on potentially unsafe opioid and CNS combination therapy and contact their prescribers to reassess therapy and determine if dose reductions, discontinuation of potentially unsafe agents, or substitution for less dangerous medications are necessary. Third-party payers' pharmacy and medical costs could decrease, since these members tend to be on multiple medications and high utilizers of medical resources. ${ }^{9-12}$ Hansen et al. (2011) reported that nonmedical use of prescription opioids costs the U.S. economy $\$ 53.4$ billion, mainly due to lost productivity ( $\$ 42$ billion), followed by criminal justice costs ( $\$ 8.2$ billion), drug abuse treatment ( $\$ 2.2$ billion), and medical complications (\$944 million). ${ }^{13}$

The objective of this study was to determine the effectiveness of a retrospective DUR program among members whose claims history suggested potentially unsafe opioid and CNS combination therapy. This DUR identified members who were taking high doses of opioid analgesics concomitantly with other opioid analgesics, benzodiazepines, or antidepressants and encouraged their prescribers to reassess combination therapy.

\section{Methods}

This pre-post study utilized pharmacy claims data from 2.6 million commercially insured members enrolled in a Midwest Blue Cross Blue Shield plan. To be eligible for analysis, members were required to be at least aged 18 years as of August 30, 2013, and continuously enrolled from May 2, 2013, through February 15, 2014. The study timeline is shown in Figure 1.

Pharmacy claims were queried to identify members with an opioid claim at least 200 morphine equivalent dose (MED) daily and a concurrent supply of another opioid, benzodiazepine, or antidepressant from May 2, 2013, through August 30, 2013 (120-day preintervention period). Opioid, benzodiazepine, and antidepressant claims were identified using American Hospital Formulary System (AHFS) pharmacologic therapeutic classification codes (28:08.08 Opiate Agonists, 28:08.12 Opiate Partial Agonists, 28.24.08 Benzodiazepines, 28:12.0 Benzodiazepines, and 28:16.04 Antidepressants).

The following exclusion criteria were applied: members belonging to commercial groups requiring permission on claims data analyses, missing or invalid prescriber information, presence of pharmacy claims indicating malignancy, or human immunodeficiency virus (HIV) or acquired immunodeficiency syndrome (AIDS) during the 2 years prior to the preintervention period. HIV and cancer drugs were identified by AHFS codes 8:18.08 Antiretrovirals and 10:00 Antineoplastics, respectively. Claims for days' supply less than 20 were excluded to capture chronic therapy because these members were at highest risk for opioid overdose.

Identified members were targeted for the retrospective DUR program. The DUR involved a provider-directed intervention for the most recent prescriber of a high-dose opioid for the identified member. In October 2013, prescribers received a mailing via the U.S. Postal Service, containing a memberspecific letter, medication profile, and satisfaction survey to 
Commercially insured members at least aged 18 years on last day of preintervention period $n=2,236,243$

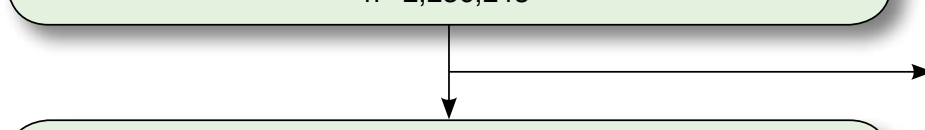

Members with an opioid claim during the 120-day preintervention period $n=415,319$

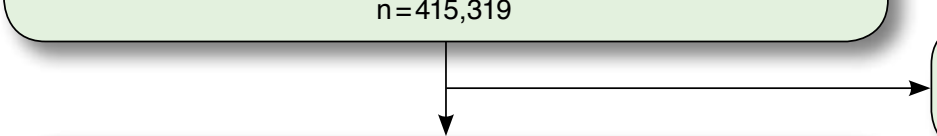

Members after excluding those with pharmacy claims indicating HIVIAIDS or cancer during 2 years prior to last day of 120-day preintervention period $n=406,939$
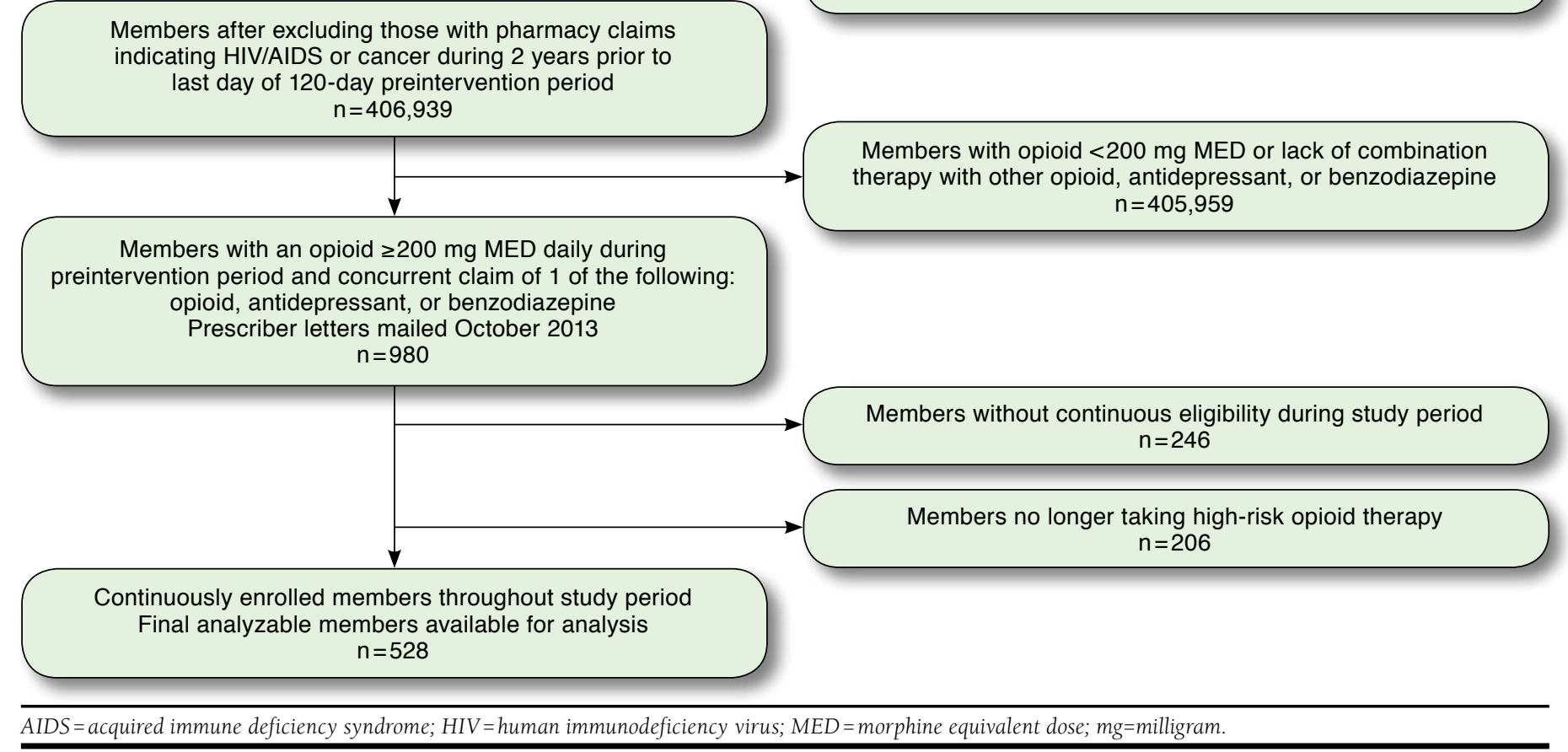

Members with opioid $<200$ mg MED or lack of combination therapy with other opioid, antidepressant, or benzodiazepine

Members with pharmacy claims indicating HIVIAIDS or cancer during 2 years prior to last day of 120 -day preintervention period $\mathrm{n}=8,380$

determine the prescriber-perceived clinical value of the program (see the Appendix, available in online article). Prescribers were asked to reevaluate the members' pain management therapies. The questionnaire survey was developed by researchers and reviewed internally by a medical director (physician) and pharmacy clinical director (pharmacist) for clarity and brevity. Revisions were made based on recommendations. The survey included multiple choice and free response questions. Participation was voluntary with no incentives offered to respondents, and surveys were returned via fax.

Criteria were reapplied to identify members still meeting criteria 120 days postintervention (February 15, 2014) to assess the effectiveness of the retrospective DUR program. A 120-day preintervention and postintervention time period was selected to capture 90-day fills. Members were categorized based on their combination therapies. For example, opioid/antidepressant indicated that a member took at least 1 opioid and at least 1 antidepressant. Categories were as follows: (a) opioid/opioid, (b) opioid/benzodiazepine, (c) opioid/antidepressant, and (d) opioid/benzodiazepine/antidepressant. Statistical testing data for member characteristics are presented as means with standard deviations or frequencies with percentages. Paired samples t-test was used to compare differences from preintervention to postintervention. A $P$ value of $<0.05$ was used to determine statistical significance.

\section{Results}

Figure 2 shows the flow of members in the study. From the 2,236,243 eligible members aged 18 years and older, 980 met DUR criteria. Among the 980 members meeting 


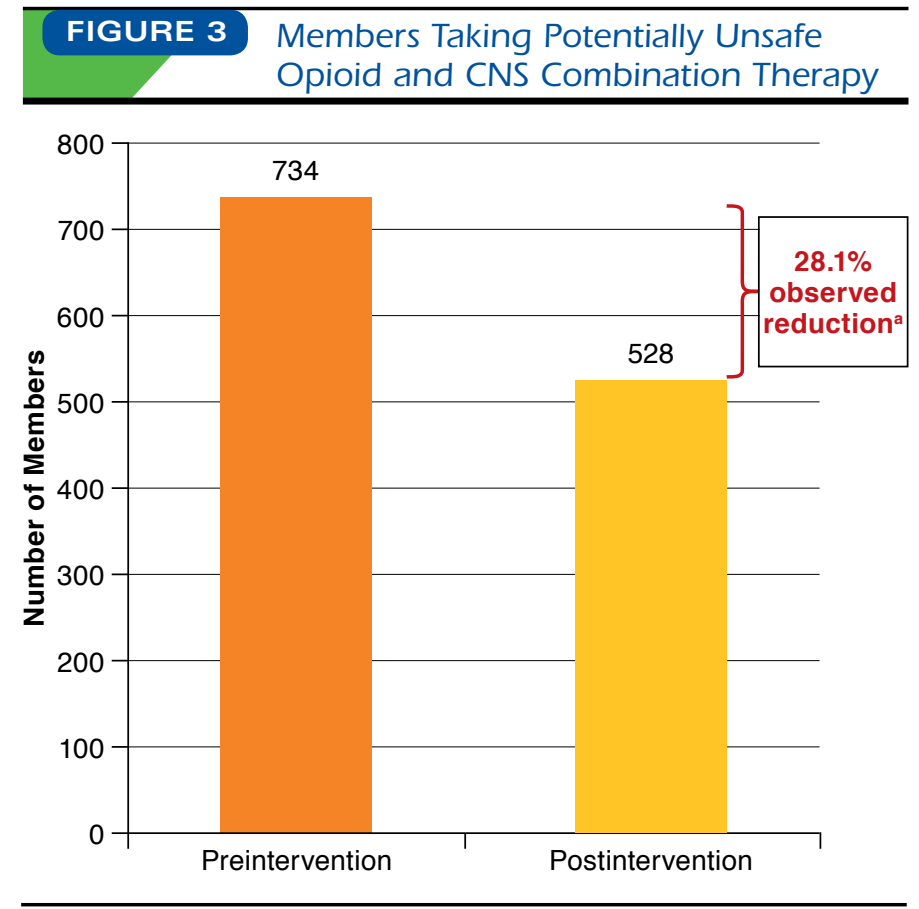

a Of the 980 members meeting DUR, 246 members discontinued Blue Cross Blue Shield pharmacy insurance and were excluded from postintervention analysis. CNS = central nervous system; DUR = drug utilization review.

DUR criteria, distribution of prescriber specialty was family medicine (25.9\%), physical medicine and rehabilitation (14.4\%), internal medicine (13.0\%), pain (9.2\%), anesthesiology (7.0\%), other (8.8\%), and unknown (21.7\%). High-dose opioids most commonly identified by the DUR were oxycodone extended release $(27.6 \%)$, morphine sulfate extended release (17.7\%), and fentanyl patch (13.1\%). A total of 200 MED daily was considered a high dose, according to the American Pain Society and American Academy of Pain Medicine..$^{14,15}$ The study sample consisted of 528 members aged 18 years and older, who were continuously enrolled from May 2, 2013, through February 15,2014 , with an opioid claim of at least 200 MED daily and a concurrent supply of another opioid, benzodiazepine, or antidepressant during the preintervention and postintervention periods. Although 980 members were targeted for the retrospective DUR program, 246 members discontinued the Blue Cross Blue Shield pharmacy insurance and were excluded from postintervention analysis.

Members meeting DUR criteria pre- and postintervention were the focus of this study's analysis, since they represented the highest-risk members taking opioid and CNS combination therapy. A total of 206 members no longer met DUR criteria in the postintervention period, representing a $28.1 \%$ reduction in high-risk opioid use (Figure 3). Of the 206 members who were no longer high risk, 66 (32.0\%) were opioid/antidepressant; 58 (28.2\%) were opioid/opioid; 47 (22.8\%) were opioid/

\section{TABLE 1 Demographics, Opioid Exposure, and Category of Combination Therapy, $\mathrm{N}=528^{\mathrm{a}, \mathrm{b}}$}

\begin{tabular}{|c|c|c|c|}
\hline \multicolumn{4}{|l|}{ Demographics } \\
\hline Age in years, mean $\pm S D$ & \multicolumn{3}{|c|}{$52.8 \pm 10.9$} \\
\hline Male, n (\%) & \multicolumn{3}{|c|}{$276(52.3)$} \\
\hline \multicolumn{4}{|l|}{ Level of opioid exposure } \\
\hline & Preintervention & Postintervention & $P$ Value \\
\hline $\begin{array}{l}\text { Total unique opioids, } \\
\text { mean } \pm S D\end{array}$ & $1.8 \pm 0.7$ & $1.8 \pm 0.6$ & 0.213 \\
\hline $\begin{array}{l}\text { Total morphine } \\
\text { equivalents per day, } \\
\text { mean } \pm \text { SD }\end{array}$ & $395.3 \pm 315.2$ & $396.5 \pm 344.2$ & 0.847 \\
\hline \multicolumn{4}{|c|}{ Category of combination cherapy, $\mathrm{n}(\%)$} \\
\hline & Preintervention & Postintervention & $P$ Value \\
\hline Opioid/opioid & $168 \quad(31.8)$ & $172 \quad(32.6)$ & $<0.001$ \\
\hline Opioid/benzodiazepine & $112 \quad(21.2)$ & $115 \quad(21.8)$ & $<0.001$ \\
\hline Opioid/antidepressant & $165 \quad(31.3)$ & $148 \quad(28.0)$ & $<0.001$ \\
\hline $\begin{array}{l}\text { Opioid/benzodiazepine/ } \\
\text { antidepressant }\end{array}$ & $83 \quad(15.7)$ & $93 \quad(17.6)$ & $<0.001$ \\
\hline
\end{tabular}

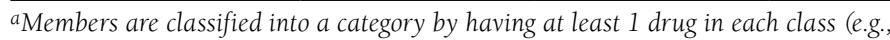
opioid/antidepressant indicates member is taking at least 1 opioid and at least 1 antidepressant).

${ }^{b}$ These members remain high risk after the DUR intervention, representing opportunities for interventions such as care management and member education regarding fraud, waste, and abuse.

$D U R=$ drug utilization review; $S D=$ standard deviation

benzodiazepine/antidepressant; and 35 (17.0\%) were opioid/ benzodiazepine. A total of 246 members were lost to followup because they discontinued pharmacy coverage during the postintervention period.

Average member age was 52.8 years, and $52.3 \%$ of the study cohort was male (Table 1). The average number of unique opioids was 1.8 for the preintervention and postintervention periods $(P=0.213)$. Change in average total MED per day was nonsignificant (395.3 vs. 396.5, $P=0.847$ ). Among these high-risk members, the level of opioid exposure remained unchanged and did not increase. Table 1 shows member distribution among the different combination therapy categories during the preintervention and postintervention periods. All categories had a small increase except the opioid/antidepressant category, which experienced a decrease.

\section{Survey Results}

The survey was sent to 671 unique prescribers managing pain therapy for the 980 members targeted for the retrospective DUR program. Of this number, 231 surveys were returned, representing a response rate of $23.6 \%$. Table 2 shows the survey results. The majority $(70.6 \%)$ of responses indicate that no change to pain management therapy was made, but $8.5 \%$ of responses indicate that opioid dose was decreased, and 14.0\% indicated some other change. For responses indicating some 


\section{TABLE 2 Survey Results}

\begin{tabular}{|c|c|c|}
\hline \multicolumn{3}{|c|}{$\begin{array}{l}\text { 1. Based on the information you received, did you change your patient's } \\
\text { pain management therapy? }\end{array}$} \\
\hline Response $(n=235)$ & $\mathrm{n}$ & $(\%)$ \\
\hline Yes, decreased the patient's opioid dose. & 20 & $(8.5)$ \\
\hline $\begin{array}{l}\text { Yes, discontinued drug(s) that interacted with the patient's } \\
\text { opioid. }\end{array}$ & 1 & $(0.4)$ \\
\hline Yes, discontinued opioid and switched to a different agent. & 1 & $(0.4)$ \\
\hline Yes, other & 33 & $(14.0)$ \\
\hline No & 166 & $(70.6)$ \\
\hline No response & 14 & $(6.0)$ \\
\hline \multicolumn{3}{|c|}{$\begin{array}{l}\text { 2. Do you routinely use your state's prescription monitoring program } \\
\text { (PMP) to see what controlled substances your patient is obtaining } \\
\text { from pharmacies? }\end{array}$} \\
\hline Response (n=231) & $\mathrm{n}$ & $(\%)$ \\
\hline Yes & 209 & $(90.5)$ \\
\hline No & 9 & $(3.9)$ \\
\hline No response & 13 & $(5.6)$ \\
\hline \multicolumn{3}{|l|}{ 3. How useful was the information you received? } \\
\hline Response $(\mathrm{n}=231)$ & $\mathrm{n}$ & $(\%)$ \\
\hline Very useful & 33 & $(14.3)$ \\
\hline Useful & 61 & $(26.4)$ \\
\hline Somewhat useful & 50 & $(21.6)$ \\
\hline Not useful & 64 & $(27.7)$ \\
\hline No response & 23 & $(10.0)$ \\
\hline \multicolumn{3}{|l|}{ 4. Please indicate your specialty ${ }^{\mathrm{a}}$} \\
\hline Response (n=248) & $\mathrm{n}$ & $(\%)$ \\
\hline Pain specialist & 91 & $(36.7)$ \\
\hline Internal medicine & 37 & $(14.9)$ \\
\hline Family medicine & 63 & $(25.4)$ \\
\hline Neurologist & 11 & $(4.4)$ \\
\hline Hospitalist & 0 & $(0.0)$ \\
\hline Physician assistant & 3 & $(1.2)$ \\
\hline Nurse pactitioner & 11 & $(4.4)$ \\
\hline Other & 19 & $(7.7)$ \\
\hline No response & 13 & $(5.2)$ \\
\hline
\end{tabular}

other change was made, $30.3 \%$ respondents planned to address therapy with members or perform a urine screen; $27.3 \%$ provided specific clinical rationale for therapy; and 24.2\% discontinued a medication or reported making a therapeutic change. Most survey respondents (90.5\%) reported routine use of their states' prescription monitoring programs when prescribing a controlled substance, and $62.3 \%$ reported that the information received was useful. Pain specialists (36.7\%) were most common among survey respondents, followed by family medicine (25.4\%) and internal medicine (14.9\%).

\section{Discussion}

This study showed that a retrospective DUR program targeting commercially insured members can result in a $28.1 \%$ decrease in potentially unsafe opioid and CNS combination therapy. High-dose opioids most commonly identified by the DUR were oxycodone extended release (27.6\%), morphine sulfate extended release (17.7\%), and fentanyl patch (13.1\%). Such findings are consistent with the MassHealth DUR program in Massachusetts, which identified the necessity for a management strategy regarding long-acting opioid analgesics (oxycodone extended release, morphine sulfate extended release, fentanyl, and methadone).$^{16}$ As a result of the MassHealth DUR program, a prior authorization was implemented for all highdose, long-acting opioid analgesics.

A targeted retrospective DUR program can be one of many different approaches that collectively address the opioid mortality epidemic. Additional strategies include lock-in programs in which controlled substance claims of a high-risk member is reimbursed only if a specific prescriber and pharmacy is used. ${ }^{17}$ Such strategy is more common among Medicaid plans, and lock-in programs could potentially benefit the highestrisk members still meeting our DUR criteria postintervention. Connecticut's DUR Board observed a savings of \$3.7 million and \$2.4 million in 2009 and 2011, respectively, when examining results of its retrospective DUR programs and lock-in programs combined. ${ }^{18}$

Among the 980 members meeting DUR criteria in our study, distribution of prescriber specialty was family medicine (25.9\%), physical medicine and rehabilitation (14.4\%), internal medicine (13.0\%), pain (9.2\%), anesthesiology $(7.0 \%)$, other (8.8\%), and unknown (21.7\%). Our retrospective DUR program may serve as a selection tool for prescribers who may benefit from academic detailing, as well as identify members that can be targeted for care management and member education regarding fraud, waste, and abuse. Although pain specialists were managing pain therapy for $9.2 \%$ of members targeted for the DUR, they were the largest group among survey respondents (36.7\%). Pain specialists were very responsive regarding a retrospective DUR program targeting high-risk opioid use.

Our retrospective DUR program identified members taking potentially unsafe opioid and CNS combination therapy. Interactions of such drug combinations can potentially result in respiratory depression and drug overdose death. The literature has shown that drug interactions involving opioids are associated with higher health care costs. ${ }^{9}$ Pergolizzi et al. (2014) found that monthly health care costs were significantly greater by $\$ 609$ among patients exposed to a potential drugdrug interaction of clinical significance compared with those not exposed. ${ }^{19}$ Summers et al. (2011) found significantly higher (\$667) average 6-month health care costs among patients exposed to opioid drug interactions compared with patients without such drug interactions. ${ }^{20}$ Although these studies focused on opioid drug interactions related to the cytochrome P450 pathway, such findings provide insight on costs associated with opioid drug interactions.

In addition to retrospective DUR programs that can identify potentially unsafe opioid and CNS combination therapy, prescribers and pharmacists can utilize PDMPs, which identify controlled substances that members are obtaining from 
pharmacies. Health care professionals are able to determine if a member is receiving potentially unsafe drug combinations that otherwise may be unknown. Academic detailing efforts can be employed to encourage prescribers to use these resources when prescribing controlled substances. Our survey results showed that $90.9 \%$ of respondents reported routine use of their state's PDMP when prescribing a controlled substance. Prescribers are utilizing PDMPs to appropriately manage their patients.

\section{Limitations}

The current study is not without limitations. First, the study used pharmacy claims data, which do not provide information regarding adherence or whether the member is actually taking the medication. Patient-specific characteristics captured by medical claims were not included, which could potentially illuminate factors that may be driving therapy change. Second, data are limited to a commercial population in the U.S. Midwest; therefore, findings may not be generalizable to Medicare/Medicaid populations or other geographic regions. Third, members often elect to pay cash for controlled substances, and this study was not able to capture cash transactions not billed through insurance. Fourth, response bias may be present among survey respondents, since the intervention and survey were administered by the health plan providing reimbursement to physicians. Fifth, there was no direct comparison group. Rather, the control was the historical claims experience of each member. The $28.1 \%$ decrease in potentially unsafe opioid use cannot be attributed solely to the intervention; the decrease may have occurred because of other factors that may impact opioid use, including disease severity and concomitant alcohol use. This limitation is inherent to prepost study designs, but pre-post design in this study was used because the intervention was implemented to all members meeting criteria for potentially unsafe drug therapy in the health plan's commercial population. Lastly, survey response rate was $23.6 \%$. Future research in this area should focus on the patient and prescriber factors that are predictive of positive postintervention changes to opioid therapy.

\section{Conclusions}

$\overline{\text { Commercial health plans can reduce risk of adverse effects and }}$ death associated with high-dose opioid analgesics used in combination with other CNS sedating agents. A $28.1 \%$ reduction in potentially unsafe opioid and CNS combination therapy was observed after implementing a retrospective DUR program targeting high-risk opioid use. Because the drug overdose epidemic is the leading cause of unintentional death in the United States, managed care organizations are well positioned to use multiple strategies such as care management and academic detailing, as well as member education regarding fraud, waste, and abuse, as follow-up to a retrospective DUR program for a comprehensive approach to further manage and reduce high-risk opioid use.

\section{Authors}

NABEEL QURESHI, PharmD, MPH, is Clinical Pharmacist; ALEXANDRA TUNGOL LIN, PharmD, is Clinical Pharmacist; and LAURIE A. WESOLOWICZ, PharmD, is Director, Pharmacy Services Clinical, Blue Cross Blue Shield of Michigan, Detroit. CHI-MEI LIU, MA, MBA, is a PhD Candidate, Department of Clinical, Social, and Administrative Sciences, University of Michigan, Ann Arbor.

AUTHOR CORRESPONDENCE: Nabeel Qureshi, PharmD, MPH, Clinical Pharmacist, Blue Cross Blue Shield of Michigan, 600 E. Lafayette Blvd., Mail Code 512C, Detroit, MI 48226.

Tel.: 313.448.7613; Fax: 866.393.8133; E-mail: nqureshi@bcbsm.com.

\section{DISCLOSURES}

The authors have no financial interest or affiliation with any company, product, or service listed in this article. The source of funding for this research was Blue Cross Blue Shield of Michigan.

Study concept and design were primarily contributed by Wesolowicz and Tungol Lin, with assistance from Qureshi and Liu. Data were collected by Qureshi and Tungol Lin and interpreted by Qureshi, Tungol Lin, and Liu. The manuscript was written and revised by Qureshi and Tungol Lin.

\section{ACKNOWLEDGMENTS}

The authors thank Andrew Bugelli, Sandra Logan, and Deepa MeenakshiSundaram at Blue Cross Blue Shield of Michigan for performing data extraction and manipulation to create analysis datasets based on research protocols provided by the authors.

\section{REFERENCES}

1. Lembke A. Why doctors prescribe opioids to known opioid abusers. N Engl J Med. 2012;367(17):1580-81. Available at: http://www.nejm.org/doi/ pdf/10.1056/NEJMp1208498. Accessed August 18, 2015.

2. Centers for Disease Control and Prevention. FastStats. Accidents or unintentional injuries. Available at: http://www.cdc.gov/nchs/fastats/accidentalinjury.htm. Accessed August 28, 2015.

3. Centers for Disease Control and Prevention. About compressed mortality, 1999-2013. CDC Wonder. Available at: http://wonder.cdc.gov/cmf-icdlo. html. Accessed August 18, 2015

4. Kunins HV, Farley TA, Dowell D. Guidelines for opioid prescription: why emergency physicians need support. Ann Intern Med. 2013;158(11):841-42.

5. Bohnert AS, Valenstein M, Bair MJ, et al. Association between opioid prescribing patterns and opioid overdose-related deaths. JAMA.

2011;305(13):1315-21. Available at: http://jama.jamanetwork.com/article. aspx?articleid=896182. Accessed August 18, 2015.

6. Jones CM, Mack KA, Paulozzi LJ. Pharmaceutical overdose deaths, United States, 2010. JAMA. 2013;309(7):657-59. Available at: http://jama. jamanetwork.com/article.aspx?articleid=1653518. Accessed August 18, 2015.

7. Centers for Disease Control and Prevention. Injury prevention \& control: prescription drug overdose. Understanding the epidemic. August 17, 2015. Available at: http://www.cdc.gov/drugoverdose/epidemic/index.html. Accessed August 26, 2015.

8. Ho MJ, Venci J. Improving the success of mailed letter intervention programs to influence prescribing behaviors: a review. J Manag Care Pharm. 2012;18(8):627-49. Available at: http://www.amcp.org/WorkArea/ DownloadAsset. aspx?id=15780. 


\section{Effectiveness of a Retrospective Drug Utilization Review on Potentially Unsafe Opioid and Central Nervous System Combination Therapy}

9. White AG, Birnbaum HG, Mareva MN, et al. Direct costs of opioid abuse in an insured population in the United States. J Manag Care Pharm. 2005;11(6):469-79. Available at: http://www.amcp.org/data/jmcp/3.pdf.

10. Jan SA. Introduction: landscape of opioid dependence. J Manag Care Pharm. 2010;16(Suppll-b):S4-S8. Available at: http://amcp.org/WorkArea/ DownloadAsset.aspx?id=8281.

11. Rasu RS, Vouthy K, Crowl AN, et al. Cost of pain medication to treat adult patients with nonmalignant chronic pain in the United States. J Manag Care Spec Pharm. 2014;20(9):921-28. Available at: http://www.amcp.org/ WorkArea/DownloadAsset.aspx?id=18469.

12. Anastassopoulos KP, Chow W, Tapia CI, et al. Economic study on the impact of side effects in patients taking oxycodone controlled-release for noncancer pain. J Manag Care Pharm. 2012;18(8):615-26. Available at: http:// www.amcp.org/WorkArea/DownloadAsset.aspx?id=15779.

13. Hansen RN, Oster G, Edelsberg J, Woody GE, Sullivan SD. Economic costs of nonmedical use of prescription opioids. Clin J Pain. 2011;27(3):194-202.

14. American Pain Society Quality of Care Committee. Quality improvement guidelines for the treatment of acute pain and cancer pain. JAMA. 1995;274(23):1874-80.
15. Chou R, Fanciullo G, Fine P, et al. Clinical guidelines for the use of chronic opioid therapy in chronic noncancer pain. J Pain. 2009;10(2):113-30. Available at: http://www.ncbi.nlm.nih.gov/pmc/articles/PMC4043401/. Accessed August 18, 2015.

16. Garcia MM, Angelini MC, Thomas T, Lenz K, Jeffrey P. Implementation of an opioid management initiative by a state Medicaid program. J Manag Care Spec Pharm. 2014;20(5):447-54. Available at: http://www.amcp.org/ WorkArea/DownloadAsset.aspx?id=18020.

17. Jeffrey PL, Lenz KL. The opiate dilemma. J Manag Care Spec Pharm. 2014;20(5):437-38. Available at: http://www.amcp.org/WorkArea/ DownloadAsset.aspx?id=18018.

18. Roberts AW, Skinner AC. Assessing the present state and potential of Medicaid controlled substance lock-in programs. J Manag Care Spec Pharm. 2014;20(5):439-46. Available at: http://www.amcp.org/WorkArea/ DownloadAsset. aspx?id=18019.

19. Pergolizzi JV Jr, Ma L, Foster DR, et al. The prevalence of opioid-related major potential drug-drug interactions and their impact on health care costs in chronic pain patients. J Manag Care Spec Pharm. 2014;20(5):467-76. Available at: http://www.amcp.org/WorkArea/DownloadAsset. aspx?id=18022.

20. Summers KH, Puenpatom RA, Rajan N, Ben-Joseph R, Ohsfeldt R. Economic impact of potential drug-drug interactions in opioid analgesics. J Med Econ. 2011;14(4):390-96. 


\section{APPENDIX Satisfaction Survey for Providers}

1. Based on the information you received, did you change your patient's pain management therapy?

_ Yes, decreased the patient's opioid dose.

_ Yes, discontinued $\operatorname{drug}(\mathrm{s})$ that interacted with the patient's opioid.

__ Yes, discontinued opioid and switched to a different agent.

Y Yes, other (please specify):

No

2. Do you routinely use your state's prescription monitoring program (PMP) to see what controlled substances your patient is obtaining from pharmacies?

Nos

3. How useful was the information you received? ( $1=$ very useful, $2=$ useful, $3=$ somewhat useful, $4=$ not useful)

$\begin{array}{llll}1 & 2 & 3 & 4\end{array}$

4. Please indicate your specialty:

___ Pain specialist

___ Internal medicine

___ Family medicine

__ Neurologist

__ Hospitalist

___ Physician's assistant

__ Nurse practitioner

__ Other (please specify):

5. Comments: 